\title{
ANALYSIS OF LITHUANIAN CREDIT DEFAULT SWAPS
}

\author{
Arvydas KREGZDE ${ }^{1}$, Gediminas MURAUSKAS ${ }^{2}$ \\ ${ }^{1}$ Department of Differential Equations and Numerical Analysis, \\ Faculty of Mathematics and Informatics, Vilnius University, \\ Naugarduko g. 24, LT-03225 Vilnius, Lithuania \\ ${ }^{2}$ Department of Econometric Analysis, Faculty of Mathematics \\ and Informatics, Vilnius University, Naugarduko g. 24, \\ LT-03225 Vilnius, Lithuania \\ E-mails: ${ }^{1}$ arvydas.kregzde@mif.vu.lt (corresponding author); \\ ${ }^{2}$ gediminas.murauskas@mif.vu.lt
}

Received 12 July 2013; accepted 24 January 2014

\begin{abstract}
This paper studies international sovereign Credit Default Swaps (CDS) market focusing attention to the CDS of Central and East Europe. The main purpose of the study was to perform detail analysis of Lithuanian CDS in the global capital market. We compared the CDS markets of other countries and found some commonalities between them. We study the credit curve produced by CDS and volatility of CDS. A great attention is paid to investigate the relationship of CDS and the government bond market. Analysis of finding a leading role of CDS and the bond markets in the price discovering process is made. A leading market for different periods is found by using the Vector Error Correction model. Our main finding is that during the volatile period price discovery takes place in the bond market and in the calm period price discovery is observed in the CDS market. Disclosed relationship between CDS spreads and Eurobonds yield risk premium gives an additional decision making tool for sovereign debt managers.
\end{abstract}

Keywords: CDS, spread, bond, leading, credit risk, Lithuania.

JEL Classification: G00, G01, G14.

\section{Introduction}

Since bankruptcy of Lehman Brothers, the government debt market has attracted particular attention. Before this event, the credit market had been focused on corporate credit risk. The sovereign debt of the developed countries had been treated as risk free. Starting from September 2008, the credit risk of the sovereigns was reassessed fundamentally. Credit risk of the EU countries was revised by the market on the largest scale.

Iceland was the first European country whose financial system was directly stressed by the debt crisis in October 2008. Liquidity shortage in a huge banking system of Iceland created problems to repay the country's debt. It only took a month in Novem- 
ber 2008 for the biggest bank of Latvia to go into bankruptcy stressing the country's financial system. A contingency effect immediately covered the other Baltic countries. This was a moment when the crisis has directly reached the EU countries, with further catastrophic subsequences. At the same time, the sovereign debt issues related to the banking sector shocked Ireland. That was the beginning of the sovereign debt problems in the Eurozone.

Lithuanian Credit Default Swaps (CDS), which were at the level of 5-6 basis points in August 2008, reached 850 basis points in February 2009. In order to avoid financial insolvency, Ireland and Latvia applied to the EU and IMF for financial assistance. Lithuania decided to borrow in the financial market at a very high price.

CDS spreads, as a measure of credit risk, deserve a great attention from academicians. Traditionally, research is focused on corporate CDS. There has not been much research on sovereign CDS. CDS of the Baltic countries are mentioned only in a few papers. Some of them have been produced by international institutions. Our aim is to fill the gap of shortage of the Lithuanian CDS analysis.

In this paper we provide a brief overview of the Lithuanian CDS market and CDS of other Baltic countries. We emphasize the linkage of the Baltic CDS markets. We analyse credit curves produced by the CDS of Lithuania. In this paper, we grant the greatest attention to relationship between the bond and the CDS markets in Lithuania. We discuss the behaviour of the basis which is the difference between the CDS spreads and the bonds spreads. Furthermore, we try to answer the question which market is leading in the price discovery process. In other words, does CDS react first and then the bond price adjusts to the CDS, or vice versa? We apply the Vector Error Correction Model (VECM) to find the leading market.

\section{Overview of CDS market research}

Credit derivatives are the contracts where payoff is based on creditworthiness of the company or the country. CDS is the most popular credit derivative. A value of CDS is based on the credit risk of the bonds issued by a reference entity. The reference entity can be corporate, institution or sovereign. A buyer of CDS obtains the right to sell bonds issued by the reference entity for this face value, when a credit event occurs to the seller of CDS. The buyer of CDS makes periodic payments to the seller until the end of the life of the CDS or until the credit event occurs. The payments are made on a quarterly or semi-annually basis. The amount of the payments is agreed between the seller and the buyer and this is the price of the CDS. Periodic payments are expressed as a percentage value of the face value of the bonds, and usually are called CDS spreads. The maturity of the contracts varies from 0.5 to 10 years. The most liquid contracts are observed in a 5-year segment of the market.

The CDS market counts his history starting from the early 90's. At the very beginning, underlying assets for CDS contract were corporate bonds. Later on, CDS contracts were extended to a wider class of underlying assets including sovereign debt ${ }^{1}$. Since the fi-

\footnotetext{
${ }^{1}$ Reliable statistic of CDS data from BIS is available from 2004.
} 
nancial crisis of 2008, the sovereign risk has increased and role of the sovereign CDS market has increased significantly. The CDS spread has become one of the main indicators of the sovereign risk. According to BIS (2012), the notional value of outstanding sovereign CDS contracts in July 2012 was 3 trillion U.S. dollars ${ }^{2}$.

Some investors used CDS as a tool to manage their credit exposure. Bongaerts et al. (2011) noted that banks are primarily net buyers of corporate CDS, while insurance companies and funds are mainly net sellers. At the same time CDS become an instrument of speculative deals. CDS as other derivatives can be traded without having underlying asset in the trader's portfolio. This fact enhances traders to use CDS as a tool for speculative positions.

During the sovereign debt crisis, authorities of the European Union follow developments in the sovereign CDS market very closely. In order to limit a possibility of speculative use of CDS, the EU regulation on "Short Selling and Certain Aspects of Credit Default Swaps" went into effect on November 2012 (see European Commission 2010). The document seeks to reduce uncovered sovereign CSD trading in order to avoid the risk of increasing spread spirals for sovereign debt. In fact, the document limits short selling of uncovered debt instruments and CDS protection buying. Beber and Pagano (2013) argued that bans on short selling are generally viewed as a measure which reduce market liquidity, hinder price and increase price volatility.

CDS being a powerful instrument of the risk management attracted a great attention from academic society. CDS spreads as a measure of the risk of the entity was investigated by a number of academicians.

Hull et al. (2004) analysed the relationship between CDS and credit rating announcements. They found that reviews for downgrade of the ratings contain significant information for CDS spreads, but a negative outlook of the rating does not. They established that credit spread changes and credit spread levels provide helpful information for estimation of a probability of negative credit rating changes. Remolona et al. (2008) decomposed CDS spread to default-risk and risk-premium. The default risk is a function of Standard and Poor's and Moody's rating announcements. Flannery et al. (2010) evaluated the CDS spreads of fifteen largest financial institutions. They established that CDS spreads incorporate new information as quickly as equity prices and significantly more quickly than credit ratings.

Some authors found that the country's risk which is expressed as the sovereign CDS spread has an impact on the price of the entity shares. Berndt et al. (2010) indicated that European corporate CDS are significantly related to a factor which captures what the authors call "economic catastrophe risk", which in some sense is the sovereign risk.

CDS as an investment instrument was investigated by Rauning et al. (2011). They established that the Value at Risk for a stock usually exceeds the Value at Risk for a position in the same firm's CDS.

\footnotetext{
2 The total CDS notional amount was 27 trillion U.S. dollars in July 2012.
} 
Another object of the CDS market analysis is investigation of the relationship between the bond and CDS markets. The joint behaviour of bond yield credit spreads and CDS spreads was discussed by Buhler et al. (2009).

Many papers are devoted to analysis of a leading role of two variables: CDS spreads and bond yields of the same entity. As indicated by Blanco et al. (2005) and Zhu (2006), the CDS market surpasses the bond market in price discovery for corporate entities. Forte et al. (2009) applied VECM to find out the leading indicator among three variables: stock price volatility, bond spreads and CDS spreads. They established that stocks excel CDS and bonds. Their modelling shows that CDS plays a leading role with respect to bonds. Norden and Weber (2009) proved that the CDS market contributes more to price discovery than the bond market and this effect is stronger for the US than for European firms.

A number of papers on analysis of the sovereign CDS is not very big. Research on the sovereign CDS mostly focuses on the analysis of the CDS-bond basis. The CDS-bond basis is the difference between CDS spreads and yield spreads of the bonds. Basis spreads are expressed by the formula:

$$
\text { CDS-bond basis }=\text { CDS spread }-(\text { Bond yield }- \text { Risk free rate }) .
$$

Fontana and Scheicher (2010) provided a comprehensive analysis of the euro area sovereign CDS market. They studied the CDS-bond basis maturity which is equal to 10 years. The authors have found that the co-integration between CDS and bonds has changed after the crisis of 2008. The two variables became co-integrated after the crisis, whereas they had not been co-integrated before the crisis. The authors found that the CDS-bond basis is positive for the leading euro area countries and changing the sign from period to period in the whole euro area. Partially, this fact can be explained by the "Flight to liquidity" phenomenon of the government bonds during the crisis. It pushed the yields of the bonds down and had its effect on the relationship of CDS and government bond spreads. Beirne and Fratzscher (2013) study contagion across advanced economies, treating the CDS spreads and bonds yield premium as an alternative measures of sovereign risk.

Dieckmann and Plank (2010) analysed the relationship between sovereign CDS and the country's banking system.

Varga (2009) discussed about the Hungarian CDS. A broad overview on the sovereign CDS was presented by Augustin (2012). The usefulness of sovereign CDS was presented by IMF (2013).

Mentioning of the Lithuanian CDS market can be found in several papers. Coudert and Gex (2010) analysed emerging, developed and risky countries' CDS basis spreads from 2 January 2007 to 18 March 2010. Their analysis included Lithuanian spreads as well. The authors made a conclusion that the CDS spread in emerging markets, including Lithuania, takes a leading position with respect to bonds.

In a broad study of the sovereign CDS market by IMF (2013), the Lithuanian CDS market was included as a part of the portfolio of the European sovereign CDS.

Varga (2009) studied the CDS-bond basis spread development from February 2005 to June 2008 in Hungary. In order to compare results, his analysis included some other 
countries and Lithuania among them. The author emphasised that the Lithuanian CDS figures before August 2007 were not reliable, therefore, the Lithuanian analysis did not include any data prior to this date. The author estimated that the average basis spreads for Lithuania made - 36 basis points, and the series of CDS spreads and bond spreads were co-integrated. He considered the Lithuanian CDS from August 2007 to June 2008. Lapinskas (2011) investigated interbank interest rate VILIBOR and the factors affecting its dynamic. He found that there was a strong relationship between the Lithuanian CDS and interbank interest rate VILIBOR. The conclusion was based on a correlation analysis.

\section{Lithuanian CDS}

\subsection{Lithuanian CDS market}

The government of Lithuania started to raise funds in money and capital market since 1994. Looking for more flexible financing of the government needs, Lithuania entered the international capital market at the end of 1995. This was a reason for international credit rating agencies to $\operatorname{start}^{3}$ rating Lithuania's ability to repay the debt. Later on, more possibilities to assess creditworthiness of the country appeared. Increase of the foreign debt of Lithuania over time has developed the Lithuanian CDS market. Lithuanian 5-year CDS spreads are presented in Figure 1.

The market of Lithuanian sovereign CDS has been very calm and illiquid until September 2008. Starting from this time, the Lithuanian CDS spreads started rising significantly, reacting to external shocks. Such events as bankruptcy of Lehman Brothers, banking problems in Iceland, Latvia and Ireland were reflected in the Lithuanian CDS by significant jumps up. During the period from September 2008 to February 2009, a jump from the level of 5-6 basis points to 850 basis points was observed. Volatility increased as well.

We focus our analysis on CDS years starting from September 2008. Shortage of liquidity of the market before this date makes analysis of the data senseless. Illiquidity of

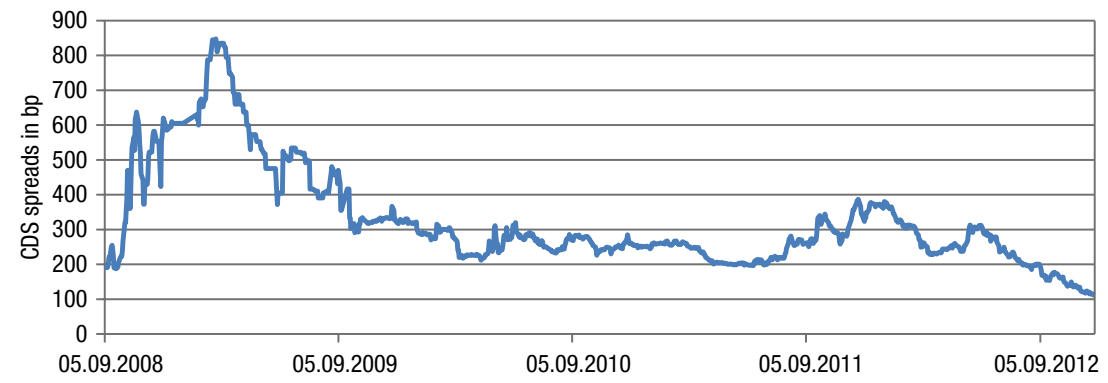

Fig. 1. Lithuanian 5-year CDS spreads from 15 September 2008 to 1 March 2013 in basis points

\footnotetext{
${ }^{3}$ Lithuanian debt was rated for the first time by Moody“s in 1996 and later on by S\&P and Fitch in 1997.
} 
the Lithuanian CDS market before September of 2008 shows stability of CDS spreads over long periods of time.

The Lithuanian CDS market becomes more complete from October 2009. Starting from this date, figures of the Lithuanian CDS are available in all ranges of maturity: 6 months and $1,2,3,4,5,7$ and 10 years $^{4}$. One of the reasons for the above was a dramatic increase of the debt of Lithuania from $15.5 \%$ to $29 \%$ of GDP in 2009.

Another reason for expansion of the Lithuanian CDS market was a growing interest in CDS of the European Union countries during the debt crisis. At that time, the interest of market participants in hedging their exposure to the sovereign risk increased.

At the end of April 2013 the outstanding gross notional amount of the Lithuanian CDS was equal to 7.9 billion $^{5}$ USD and reached $46 \%$ of the total country's debt ${ }^{6}$. Figure 2 presents the share of outstanding gross notional amount of CDS in emerging countries of the EU with respect to the sovereign debt.

High percentages of Bulgarian an Estonian CDS with respect to their sovereign debt can be explained by a small debt of these countries with respect to their GDP ${ }^{7}$. It is interesting to note that a notional amount of CDS of these countries was greater than their debt. It shows that CDS are used not only for direct hedging.

The market of Lithuanian CDS is growing rapidly. The average turnover of the Lithuanian CDS increased by $56 \%$ in notional amount ${ }^{8}$ during a period of two years. The weekly average turnover in the period from 3 September 2010 to 25 February 2011 was 31 million USD and the average number of contracts was 5 . The average turnover of CDS contracts and a number of contracts in the Baltic countries from 12 September 2012 to 22 February 2013 is presented in Table 1.

As we see from the Table 1 Lithuanian CDS market is the biggest among the Baltic countries.

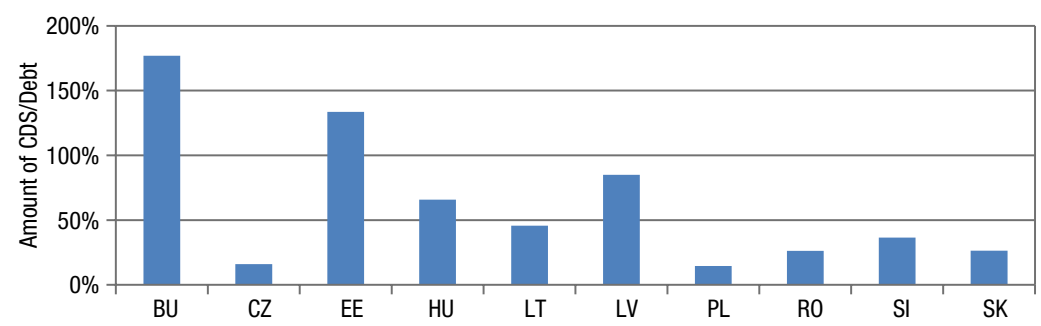

Fig. 2. Outstanding gross notional amount of CDS with respect to the sovereign debt on 26 April 2013

\footnotetext{
${ }^{4}$ Data provided by Bloomberg.

${ }^{5}$ According to DTCC data. Web page: www.dtcc.com.

${ }^{6}$ According to the Department of Statistics under the Government of the Republic of Lithuania (2013), at the end of 2012 the total Lithuanian government debt was 40.7 billion Litas (16 billion U.S. dollars).

${ }^{7}$ At the end of 2012, Bulgarian Debt to GDP was 18.5\% and Estonian Debt to GDP was $10.1 \%$ (Eurostat 2013).

${ }^{8}$ According to DTCC data. Web page: www.dtcc.com.
} 
Table 1. Weekly average of turnover in million USD and a number of contracts from 12 September 2012 to 22 February 2013 of the Baltic countries' CDS

\begin{tabular}{ccc}
\hline Country & Turnover in million USD & Number of contracts \\
\hline Lithuania & 55 & 9 \\
\hline Latvia & 39 & 5 \\
\hline Estonia & 17 & 3 \\
\hline
\end{tabular}

\subsection{Lithuanian CDS credit curve}

If CDS spreads of different maturity are known, we can build a curve where CDS spreads are expressed as a function of maturity of CDS. The curve is called a CDS curve. The curve shows how periodic payments of the buyer of the contract change depending on the maturity of a CDS contract. Taking into account that CDS express credit risk, we call this curve a credit curve. Credit curves had been built even before CDS contracts were introduced. Other market parameters expressing credit risk were used back then.

By using CDS spreads of different maturities of CDS we build credit curves of Lithuania. In Figure 3 we present the credit curve of Lithuania at the end of 2009, 2010, 2011 and 2012.

A mathematical model of the credit curve was developed by Merton in 1974. The Merton model proposed assessing the credit risk of a company by characterizing the company's equity as a call option on its assets. The Merton model proves that the credit curve is increasing for the high-quality credit levels, hump-shaped for intermediate credit quality and decreasing for low levels of credit quality. Lando and Mortensen (2005) extended investigation of credits curve for corporate CDS. Pan and Singleton (2008) analysed the impact of probability of default and recovery ratio to the term structure $^{9}$ of sovereign CDS.

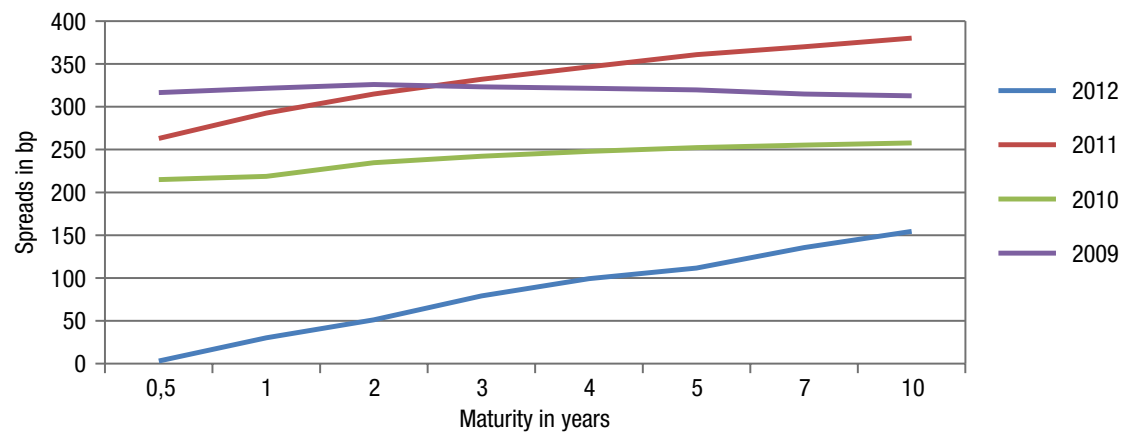

Fig. 3. Credit curve of Lithuanian CDS spreads in basis points

${ }^{9}$ The term structure is a more formal name of credit curve. 
As we can see from the Figure 3, the credit curve of the Lithuanian CDS follows the rule as described by Merton (1974). In 2009 the level of CDS spreads in Lithuania was at a high level and the credit curve was a hump shaped. In 2010 the CDS spreads decreased and the credit curve became monotonically increasing. The curve was increasing in 2011 and 2012, reflecting a decrease in CDS spreads.

The slope of the credit curve has direct implication to the slope of the yield curve of Lithuania. In 2009 short term interest rate in Lithuania reached its maximal value. In 2012 Lithuanian short term interest rate fell to its lowest level in history.

Augustin (2012) analysed the average shape of the term structure based on the sovereign CDS spreads, from May 2003 until August 2010. He grouped the countries according to their credit rating and made some statistical analysis within the groups. The author found that the mean term structure within the group with the same rating has an upward sloping shape. The increasing term structure of the three emerging countries was shown by Pan and Singleton (2008). In another exercise, Augustin (2012) grouped the countries according to 5-year CDS spreads level. Then he arrived to the outcome that for a higher level of CDS spreads the slope of the term structure can be downwarding. This conclusion is consistent with our findings in the case of Lithuania.

\subsection{Relationship of CDS of the Baltic countries}

Now we will make some statistical analysis of 5-year CDS spreads. There are some papers devoted to the studies of the CDS spread levels and volatility of CDS. Augustin (2012) perceived that if countries become less creditworthy, then volatility of their CDS spreads jump as well. We made some statistical analysis for the Lithuanian CDS spreads and volatility of CDS.

We calculated the average of the Lithuanian CDS spreads and volatility of the spreads on a quarterly basis. Our calculations cover the period from 15 September 2008 to 1 March 2013. We found that the correlation coefficient between the Lithuanian CDS spreads and volatility of the CDS spreads is equal to 0.704 . This shows that the spread level of CDS has a crucial impact on the volatility. We checked the relationship between CDS levels in the Baltic countries and volatility of CDS. The results of the relationship are presented in Table 2 .

Table 2. Correlations between CDS spreads and volatility of CDS of the Baltic countries

\begin{tabular}{lcccccc}
\hline & $\begin{array}{c}\text { LLT } \\
\text { spreads }\end{array}$ & $\begin{array}{c}\text { LT } \\
\text { volatility }\end{array}$ & $\begin{array}{c}\text { LV } \\
\text { spreads }\end{array}$ & $\begin{array}{c}\text { LV } \\
\text { volatility }\end{array}$ & $\begin{array}{c}\text { EE } \\
\text { spreads }\end{array}$ & $\begin{array}{c}\text { EE } \\
\text { volatility }\end{array}$ \\
\hline LT spreads & 1 & $0,700^{* *}$ & $0,943^{* *}$ & $0,620^{* *}$ & $0,934^{* *}$ & $0,589^{* *}$ \\
\hline LT volatility & $0,700^{* *}$ & 1 & $0,67^{* *}$ & $0,967^{* *}$ & $0,716^{* *}$ & $0,964^{* *}$ \\
\hline LV spreads & $0,943^{* *}$ & $0,670^{* *}$ & 1 & $0,621^{* *}$ & $0,926^{* *}$ & $0,608^{* *}$ \\
\hline LV volatility & $0,620^{* *}$ & $0,967^{* *}$ & $0,621^{* *}$ & 1 & $0,653^{* *}$ & $0,974^{* *}$ \\
\hline EE spreads & $0,934^{* *}$ & $0,716^{* *}$ & $0,926^{* *}$ & $0,653^{* *}$ & 1 & $0,638^{* *}$ \\
\hline EE volatility & $0,589^{* *}$ & $0,964^{* *}$ & $0,608^{* *}$ & $0,974^{* *}$ & $0,638^{* *}$ & 1 \\
\hline
\end{tabular}


We see that the correlation between spreads and volatility is very similar in each country and lies between 0.638 and 0.700 . Correlations between the countries' spreads are very tight and the pairwise correlation coefficients between the countries exceed 0.92. This can be explained by the fact that the risk of the Baltic countries' financial markets is treated as the region's systemic risk rather than the risk of individual countries.

Our next task was to check the relationship between changes of the CDS spreads in Lithuania and other Baltic states. We found that the correlation coefficient between monthly changes of the Lithuanian CDS and the Latvian CDS was equal to 0.909 and the correlation coefficient between monthly changes of the Lithuanian CDS and the Estonian CDS was equal to 0.907 .

Correlation between monthly changes of the sovereign CDS spreads was analysed by Longstaff et al. (2011). They found that the correlation between Chile and Mexico was $87 \%$, the correlation between Korea and Malaysia was $82 \%$ and the correlation between Romania and Croatia was $91 \%$. The average pairwise correlation observed over all the countries ${ }^{10}$ was $62 \%$. Authors concluded that the majority of sovereign credit risk is linked to the global factors. Our calculations show that the relationship between the Baltic countries is even greater than that found by the authors for other countries. This proves that the global financial market treats the Baltic countries as a single market.

Longstaff et al. (2011) found that the correlation of monthly changes during a crisis period is stronger. We divided the period of our consideration into two sub-periods. The first sub-period is from 15 September 2008 to 15 September 2010 and is characterized by very high CDS spreads in the Baltic countries. Another sub-period is from 15 September 2010 to 1 March 2013 and is calmer. We found that the correlation coefficients between the Lithuanian CDS and the Latvian CDS in the first and the second sub-periods were 0.924 and 0.954 respectively. The correlation coefficients between the Lithuanian and the Estonian CDS in the first and the second sub-periods were 0.952 and 0.664 respectively. Our calculation did not prove the findings of Longstaff et al. (2011), that during a crisis the correlation is stronger. The correlation between the Lithuanian and the Latvian CDS was not stronger during turmoil. A significant decrease of the correlation between the Lithuanian and the Estonian CDS during the second period can be explained by the fact that during this period Estonia became a member of the Eurozone.

\section{Analysis of CDS and bond spreads}

Now, we will focus on the analysis of the long run relationship between the Lithuanian sovereign 5-year CDS spreads and the Lithuanian bonds issued in the euro currency risk premium in yields. We calculated the risk premium in yield as a difference between bond yield and 5-year risk free rate. The role of the risk free rate was played by the 5 -year swap rate. We chose the swap rate because interest rate swaps are commonly seen as the market participants' preferred measure of the risk-free rate (see Beber et al. 2009).

10 The authors analysed 26 countries from 2000 to 2010. 
The yield of 5-year bond was calculated as the yield of a synthetic bond. We took two quite liquid bond issues. Maturity of the first bond was less and maturity of the second bond was greater than 5-years. By using a simple linear interpolation of yields of the selected bonds we calculated the yield of the synthetic bond exactly of 5-year maturity for each day of our consideration. Because of a lack of corresponding bonds we focused our investigation on the period from 15 June 2009 to 1 March 2103. We used Bloomberg's data and took a mid-rate for the swap and for the bond. In our paper, we use exactly the same maturity for CDS and the bonds. Here, it is worth to notice that this is not like A. Carboni (2011) who used 10 years' bonds and 5-years' CDS to investigate the leading role of two markets.

Firstly, we will focus on the CDS-bond basis analysis. If the CDS-bond basis is positive, then the CDS spread is greater than the bond spread. From a trader's point of view, this is a possibility to sell a bond and buy a CDS. A credit risk for the trader after such a deal does not change. If the CDS-bond basis is negative, then the bond spread is greater than the CDS spread. For a trader this is a possibility to sell a CDS and buy a bond.

We calculated the CDS-bond basis for Lithuania in the period from 15 June 2009 to 1 March 2103. The CDS-bond basis is presented in Figure 4.

We found that the CDS-bond basis is positive and equals to 10.5 basis points on the average. Despite it, its standard deviation is big and equals to 56. The highest value of the CDS-bond spread is equal to 102 and the smallest value is equal to - 150 . The length of the period when the CDS-bond basis was negative is almost equal to the length of the period when the CDS-bond basis was positive. A similar effect was found by Fontana and Scheicher (2010). They found that the sign of the CDS-bond basis is not constant for the Eurozone countries. Their conclusion was that for weaker Eurozone countries the sign of CDS-bond spread changes with economic environment and tolerance of risk in the market. For less risky Eurozone countries the CDS-bond spread is mostly on a positive side.

Now we will investigate the reaction of the CDS market and the bond market to the changes in credit risk of Lithuania. Both markets react to the external factors that can

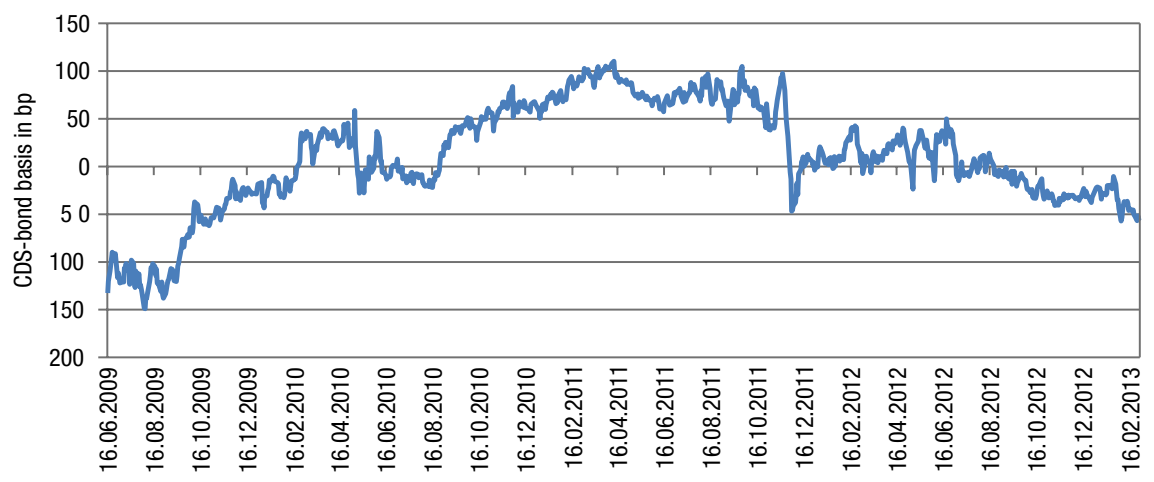

Fig. 4. CDS-bond basis in basis points from 15 June 2009 to 1 March 2013 
affect creditworthiness of Lithuania as well as internal events in Lithuania. Our aim is to find out which of the two markets reacts first. In fact, we are going to make a lead- lag analysis between the CDS spreads and the bond spreads.

First, we apply the augmented Dickey-Fuller (ADF) test and check co-integration of the series in the period from 15 June 2009 to 1 March 2013. The null-hypothesis of a unit root for both series is not rejected at any conventional significance, whereas the null of non-stationary first differences is rejected at the 0.01 -level, i.e. both series integrated once, I(1). We reject the null hypothesis of no co-integration ${ }^{11}$ among the series at the 0.01-level. It means that a linear combination of the CDS spreads and the bond spreads is stationary.

We apply the VECM described by Gonzalo and Granger (1995) which can be expressed in the following way:

$$
\begin{gathered}
\Delta \mathrm{CDS}_{t}=\lambda_{1}\left(\mathrm{Z}_{t-1}\right)+\sum_{j=1}^{p} \alpha_{1, j} \Delta \mathrm{CDS}_{t-j}+\sum_{j=1}^{q} \beta_{1, j} \Delta \mathrm{BS}_{t-j}+\varepsilon_{1, t}, \\
\Delta \mathrm{BS}_{t}=\lambda_{2}\left(\mathrm{Z}_{t-1}\right)+\sum_{j=1}^{p} \alpha_{2, j} \Delta \mathrm{CDS}_{t-j}+\sum_{j=1}^{q} \beta_{2, j} \Delta \mathrm{BS}_{t-j}+\varepsilon_{2, t}, \\
\mathrm{Z}_{t-1}=\operatorname{CDS}_{t-1}-\alpha_{0}-\alpha_{1} \mathrm{BS}_{t-1},
\end{gathered}
$$

where $\mathrm{CDS}_{t}$ means the CDS spread at the moment $t ; \Delta \mathrm{CDS}_{t}$ is the difference between the CDS spread at the moment $t$ and $t+1 ; \mathrm{BS}_{t}$ is the difference between a synthetic bond yield and the 5-year swap rate; $Z_{t-1}$ is the long run error correction term that describes a deviation of the CDS and the bond spreads.

The idea of the model is based on the fact that the CDS spreads and the cash market spreads follow a long run relationship between two markets which is expressed by the function $\mathrm{Z}_{t}$. We estimated the model's parameters by using a one-year rolling window of daily data starting 1 July 2010.

The values of coefficients $\lambda_{1}$ and $\lambda_{2}$ play the core role in the model. Depending on the values of these coefficients we decide which market is leading. First of all, we check how significant these coefficients are. If one of the coefficients is not statistically significant, then we make a decision to consider only the coefficient which is significant. We find that both coefficients $\lambda_{1}$ and $\lambda_{2}$ are significant during the periods concerned.

The relationship between coefficients $\lambda_{1}$ and $\lambda_{2}$ shows which market reacts faster to the changes of the credit quality of the country. For this reason we use the ratio introduced by Gonzalo and Granger (1995):

$$
\mathrm{GG}=\frac{\lambda_{2}}{\lambda_{2}-\lambda_{1}} .
$$

The leading role of CDS is characterized by a positive coefficient $\lambda_{2}$. A negative coefficient $\lambda_{1}$ means that the leading role is played by the bond market. Therefore, in case the Gonzalo and Granger ratio is greater than 0.5 , we have that $\lambda_{2}>-\lambda_{1}$ and the reac-

${ }^{11}$ We apply Johansen co-integration rank test between series. 
tion of the CDS market is faster. In case the ratio is less than 0.5 , we have that $\lambda_{2}<-\lambda_{1}$ meaning that the bond market has a leading role.

The idea of the model is very simple. Deviation of CDS and bond spreads from their long run relationship at the moment $t-1$ implies a high probability that it will come back at the moment $t$. There are two extreme options to restore the long run relationship. The first option is that the CDS spread will change. The second option is that the bond spread will change. The change of the price of the bond means that the CDS was the first and the change of the CDS spreads means that the bond was the first in discovering the price. The change of the price of the bond to restore the long run relationship is characterised by a positive value of $\lambda_{2}$. Therefore, a positive value of $\lambda_{2}$ means the leading role of CDS in the price discovering process.

It should be noticed that in the equation $Z_{t-1}$ which expresses the relationship between the CDS and the bond spreads, the variables $\mathrm{CDS}_{t-1}$ and $\mathrm{BS}_{t-1}$ appear with opposite signs. Therefore, a negative value of coefficient $\lambda_{1}$ means the leading role of the bond.

In case $\lambda_{1}$ is negative and $\lambda_{2}$ is positive, the GG ratio helps us to estimate the impact of the coefficients. In terms of the GG ratio, a value of GG close to zero means the leading role of the bond. If GG is close to 1, then the leading role is taken by CDS. The value of GG close to 0.5 says that both markets are leading and we cannot say which is the first. The coefficient estimates with t-statistics are presented in Table 3.

During the period from July 2010 to April 2011 both the coefficients were negative. A negative value of $\lambda_{1}$ and a low value of GG enable us to state that the bond market was leading during the period concerned. During the period from April 2011 to February 2012 the coefficient $\lambda_{1}$ was negative and the coefficient $\lambda_{2}$ was positive. This means that both markets had a claim to be leading. The value of GG being lower than 0.5 shows that the main leading role is played by the bond market. The leading role of the CDS was observed in the period from February 2012 to March 2013. This follows from the fact that $\lambda_{2}$ was positive and significantly greater than $\left(-\lambda_{1}\right)$. The value of the ratio GG close to 1 confirms the leading role of the CDS market.

During the first period, the Lithuanian CDS spreads were quite stable (see Fig. 1). The second period is characterized by the uncertainty of restructuring of Greece debt which implied increase of the Lithuanian CDS spreads. During these two periods we observed

Table 3. Values of coefficients and GG ratio

\begin{tabular}{cccc}
\hline Period & July $2010-$ April 2011 & April $2011-$ February 2012 & February $2012-$ March 2013 \\
\hline$\lambda_{1}$ & $-0,1336$ & -0.0439 & 0,0034 \\
\hline t-stat & {$[-97,73]^{* *}$} & {$[-24,22]^{* *}$} & {$[3.71]^{*}$} \\
\hline$\lambda_{2}$ & $-0,0316$ & 0,0157 & 0,0827 \\
\hline t-stat & {$[-20.84]^{* *}$} & {$[6,6]^{* *}$} & {$[85,46]^{* *}$} \\
\hline GG & $-0,3098$ & 0,2634 & 1.0429 \\
\hline Leading & Bond & Bond & CDS \\
\hline
\end{tabular}


the leading role of bonds in the price discovering process. The role of CDS became more important during the second period, yet bonds still kept the leading role. The third period is characterized by decreasing risk of Lithuania which is expressed by lower CDS spreads. During this period the CDS market took the leading role.

IMF (2013) found that the CDS spreads in emerging markets had been taking leading positions since 2012. Our calculations coincide with the finding of IMF. It is worth to notice that Coudert and Gex (2010) made a conclusion that the CDS spread in emerging markets including Lithuania took a leading position with respect to bonds in 2007-2010.

Our calculations show that both coefficients $\lambda_{1}$ and $\lambda_{2}$ are statistically significant. It should be noticed that one of the coefficients $\lambda_{2}$ or $\lambda_{1}$ found by Fontana and Scheicher 2010 was insignificant for each country of their consideration. In the paper mentioned, the authors investigated several Eurozone countries in the period from September 2008 to June 2010. They found that the bond took leading positions in stronger Eurozone countries and CDS took leading positions in weaker Eurozone countries.

\section{Conclusions}

The paper studies international sovereign CDS market focusing attention to CDS of Central and East Europe. We perform detail analysis of Lithuanian CDS and relationship of CDS spreads and Eurobonds yield premium. We found that the liquidity characterized by the turnover of US\$55m per week is low compared to the average liquidity of the credit derivatives, yet it is high in Lithuanian standards. A notional amount of the Lithuanian CDS share consists of $46 \%$ of the sovereign debt.

Volatility of the Lithuanian CDS spreads is related to the level of the spreads. The higher is the level of the spreads, the higher is the volatility. The credit curve of Lithuanian CDS increases during calm period of time and is hump-shaped for intermediate credit levels.

The CDS markets of the Baltic countries are very interrelated. A strong correlation exists between the CDS spreads and volatility of the spreads.

There is a strong co-integration between CDS spreads and the spreads of Lithuanian bonds denominated in the euro. The CDS-bond basis was on a positive side for almost half time and on a negative side for another half time. There is no evidence that CDS spread could be higher than the bond spread or vice versa. This is different from the leading EU countries, where the CDS bond spread is mostly positive.

The lead-lag analysis shows that the leading role of CDS spreads and the bond spreads changes over time. From July 2010 to February 2012 the bond spreads were leading against the CDS spreads. From February 2012 to March 2013 the risk of Lithuania was falling and the CDS spreads were leading against the bond spreads. Our observation is that in the case of Lithuania the leading role depends on external factors. When there is an uncertainty around, the leading role is taken by the bond market. The dependence on external factors is greater than that in the developed countries. In terms of the risk side of countries, we argue that the country is very vulnerable to external factors. 
The results of the study have practical application for investors and issuers of sovereign debt. Disclosed relationship between CDS spreads and Eurobonds yield risk premium gives an additional decision making tool for sovereign debt managers in choosing the timing and amount for issuing new debt.

Later studies of international CDS market could explore contagion effects of sovereign credit risk of emerging economies, especially of Central and East European countries.

\section{References}

Augustin, P. 2012. Sovereign credit default swap premia, Working paper [online], [cited 20 May 2013]. Available from Internet: http://papers.ssrn.com/sol3/papers

Bank for International Settlements (BIS). 2012. Statistical Release: OTC Derivatives Statistics at End-June 2012 (Basel, November) [online], [cited 23 May 2013 ]. Available from Internet: www.bis.org/publ/otc_hy1211.pdf.

Beber, A.; Brandt, M. W.; Kavavejc, K. A. 2009. Flight-to-quality or flight-to-liquidity? Evidence from the Euro-area bond market, Review of Financial Studies 22: 925-925.

http://dx.doi.org/10.1093/rfs/hhm088

Beber, A.; Pagano, M. 2013. Short-selling bans around the world: evidence from the 2007-09 crisis, Journal of Finance, 68(1): 343-381.

Beirne, J.; Fratzscher, M. 2013. The pricing of sovereign risk and contagion during the European sovereign debt crisis, Journal of International Money and Finance 34: 60-82.

http://dx.doi.org/10.1016/j.jimonfin.2012.11.004

Berndt, A.; Obreja, I. 2010. Decomposing European CDS returns, Review of Finance (14): 189233. http://dx.doi.org/10.1093/rof/rfq004

Blanco, R.; Brennan, S.; Marsh, I. W. 2005. An empirical analysis of the dynamic relation between investment-grade bonds and credit default swaps, Journal of Finance 60(5): 2255-2281. http://dx.doi.org/10.1111/j.1540-6261.2005.00798.x

Bongaerts, D.; De Jong, F.; Driessen, J. J. 2011. Derivative pricing with liquidity risk: theory and evidence from the credit default swap market, Journal of Finance 66(1): 203-240.

Buhler, W.; Trapp, M. 2009. Explaining the bond-CDS basis - the role of credit risk and liquidity, CFR Working Paper No 09-12.

Carboni, A. 2011. The sovereign credit default swap market: price discovery, volumes and links with banks' risk premia, Banca D'Italia, Working paper 821.

Coudert, V.; Gex, M. 2010. Credit default swap and bond markets: which leads the other?, Banque de France Financial Stability Review - Derivatives, Financial Innovation and Stability 14: 161-167.

Department of Statistics under the Government of the Republic of Lithuania. 2013. Indicator database [Statistikos departamento prie Lietuvos Respublikos vyriausybès „Rodiklių duomenu bazès"] [online], [cited 11 June 2013]. Available from Internet: http://db1.stat.gov.lt/statbank/ default.asp? $\mathrm{w}=1280$

Dieckmann, S.; Plank, T. 2010. Default Risk of Advanced Economies: An Empirical Analysis of Credit Default Swaps during the Financial Crisis. Mimeo. Wharton School.

European Commission. 2010. Proposal for a Regulation of the European Parliament and of the Council on Short Selling and Certain Aspects of Credit Default Swaps, September 15, COM (2010) 482 Final [online], [cited 28 May 2013]. Available from Internet: http://ec.europa.eu/ internal_market/securities/short_selling_en.htm.

Eurostat. 2013. Government statistics 2012 [online], [cited 11 June 2013]. Available from Internet: http://appsso.eurostat.ec.europa.eu/nui/show.do?dataset=gov_dd_edpt1\&lang=en. 
Flannery, M. J.; Housto, J. F.; Parthoy, F. 2010.Creedit default swaps spreads as viable substitutes forcredit ratings.Univerity of Pensivalnia, Law review 158(4): 2085-2123.

Fontana, A.; Scheicher, M. 2010. An analysis of Euro area sovereign CDS and their relation with government bonds, ECB Working Paper No. 1271.

Forte, S.; Pena, S.; Juan, I. 2009. Credit spreads: an empirical analysis on the informational content of stocks, bonds, and CDS, Journal of Banking and Finance 33(11): 2013-2025.

http://dx.doi.org/10.1016/j.jbankfin.2009.04.015

Gonzalo, J.; Granger, C. 1995. Estimation of common long-memory components in cointegrated systems, Journal of Business and Economic Statistics (13): 27-35.

Hull, J.; Predescu, M.; White, A. 2004. The relationship between credit default swap spreads, bond yields, and credit rating announcements, Journal of Banking \& Finance 28(11): 2789-2811. http://dx.doi.org/10.1016/j.jbankfin.2004.06.010

IMF. 2013. Global financial stability report, April, 2013. International Monetary Fund.

Lando, D.; Mortensen, A. 2005. Revisiting the slope of the credit spread curve, Journal of Investment Management 3(4): 1-27.

Lapinskas, V. 2011. The VILIBOR-EURIBOR spread dynamics during the recent financial crisis, Ekonomika 90(4): 100-115.

Longstaff, F. A.; Pan, J.; Pedersen, L. H.;Singleton, K. J. 2011. How sovereign is sovereign credit risk?, American Economic Journal: Macroeconomics 3(2): 75-103.

Merton, R. C. 1974. On the pricing of corporate debt: the risk structure of interest rates, in Proceedings of the Thirty-Second Annual Meeting of the American Finance Association, 28-30 December 1973, New York, 449-470.

Norden, L.; Weber, M. 2009. The co-movement of credit default swap, bond and stock markets: an empirical analysis, European Financial Management 15(3): 529-562.

http://dx.doi.org/10.1111/j.1468-036X.2007.00427.x

Pan, J.; Singleton, K. J. 2008. Default and recovery implicit in the term structure of sovereign CDS spreads, The Journal of Finance 63(5): 2345-2384.

http://dx.doi.org/10.1111/j.1540-6261.2008.01399.x

Rauning, B.; Scheider, M. 2011. A value-at risk analysis of credit default swaps, Journal of Risk 13(4): 3-29.

Remolona, E.; Michela, S.; Wu, E. 2008. The dynamic pricing of sovereign risk in emerging markets: fundamentals and risk aversion, The Journal of Fixed Income 17(4): 57-71.

http://dx.doi.org/10.3905/jfi.2008.705542

Varga, L. 2009. The information content of Hungarian sovereign CDS spreads, MNB Occasional Papers No 2009/78. Central Bank of Hungary.

Zhu, H. 2006. An empirical comparison of credit spreads between the bond market and the credit default swap market, Journal of Financial Services Research 29(3): 211-235.

http://dx.doi.org/10.1007/s10693-006-7626-x

Arvydas KREGZDE is an Associate Professor in the Department of Differential equations and Numerical Analysis at Vilnius University. His academic research interest are: mathematical modelling, mathematics of finance, financial markets and government policy.

Gediminas MURAUSKAS is an Associate Professor in the Department of Econometric Analysis at Vilnius University. His recent research interests include: generalized linear mixed models, data mining. 